\title{
Employee Engagement: The Key to Improving Performance
}

\author{
Solomon Markos (Corresponding author) \\ PhD Scholar, Department of Commerce and Management Studies, Andhra University \\ Waltair, Visakhapatnam-530 003, Andhra Pradesh, India \\ Tel: 91-996-664-1683_E-mail: solomonmarkos5@yahoo.com \\ M. Sandhya Sridevi \\ Professor, Department of Commerce and Management Studies, Andhra University \\ Waltair, Visakhapatnam-530 003, Andhra Pradesh, India \\ Tel: 91-984-884-2230Ｅ-mail: sandhya.sridevi@hotmail.com
}

\begin{abstract}
Employee engagement is a vast construct that touches almost all parts of human resource management facets we know hitherto. If every part of human resources is not addressed in appropriate manner, employees fail to fully engage themselves in their job in the response to such kind of mismanagement. The construct employee engagement is built on the foundation of earlier concepts like job satisfaction, employee commitment and Organizational citizenship behaviour. Though it is related to and encompasses these concepts, employee engagement is broader in scope. Employee engagement is stronger predictor of positive organizational performance clearly showing the two-way relationship between employer and employee compared to the three earlier constructs: job satisfaction, employee commitment and organizational citizenship behaviour. Engaged employees are emotionally attached to their organization and highly involved in their job with a great enthusiasm for the success of their employer, going extra mile beyond the employment contractual agreement.
\end{abstract}

Keywords: Employee engagement, Employee commitment, Organizational citizenship behaviour, Job satisfaction

\section{Introduction}

Managers unequivocally agree that this century demands more efficiency and productivity than any other times in history. Businesses are striving to increase their performance. Managers have been grappling with many challenges to succeed putting their company ahead of competitors. To help managers manage, different scholars, researchers and consultants have been contributing their part showing the best ways they think are useful to managers. Among those suggested techniques, concepts like Total Quality Management (TQM) and Business Process Reengineering (BPR) earned recognition from many authors in the second half of twentieth century and were found helpful in increasing organizational performance by focusing on operational and process improvements. They were/still being used as tools for management in their effort to plan, execute and control of the desired changes in the operational quality.

Thanks to technology, nowadays business companies are making use of advanced techniques of operation. As sophistication of technologies continues to evolve, they pose more challenges for managers because organizations will have to need more number of employees with increased technical and professional skills. These knowledge workers can not be managed with old styles of totalitarian management. They expect operational autonomy, job satisfaction and status. It is because of these facts that attention of managers is shifting towards employees' side of organizations. From last quarter of twentieth century onwards, concepts like employee commitment and Organizational Citizenship Behaviour (OCB) started to appear on the ground that efficiency and productivity lie within the employees' ability and commitment. Managers' eye is on how to keep employees engaged in their job. Employers now realize that by focusing on employee engagement, they can create more efficient and productive workforce. Any initiatives of improvement which are taken by management can not be fruitful without wilful involvement and engagement of employees. Employee engagement as a concept is vast. This article limits itself to discuss only the basic concepts on employee engagement based on recent literatures. It has four major parts. Firstly, the article explores the evolution of the concept, its definition and how it is different from the earlier concepts such as Commitment, Organizational Citizenship Behaviour $(\mathrm{OCB})$ and job satisfaction. Secondly, the article discusses the factors or drivers leading to engagement. Thirdly, 
it details the impact of employee engagement on organizational performance indicators or business outcomes such as profitability, customer satisfaction, company growth, productivity and others pointing out its benefits and importance to organizations. Finally, the article suggests strategies the companies should take up to keep employees engaged in their jobs.

\section{Evolution of Employee Engagement and its Definition}

\subsection{Evolution of Employee Engagement}

Most references relate employee engagement to survey houses and consultancies. It is less taken as an academic construct. The concept is relatively new for HRM and appeared in the literatures for nearly two decades (Rafferty, Maben, West and Robinson, 2005; Melcrum Publishing, 2005; Ellis and Sorensen, 2007).

The construct, employee engagement emanates from two concepts that have won academic recognition and have been the subjects of empirical research-Commitment and Organizational Citizen Behaviour (OCB) (Robinson, Perryman and Hayday, 2004; Rafferty et al., 2005). Employee engagement has similarities to and overlaps with the above two concepts.

Robinson et al. (2004) state that neither commitment nor OCB reflect sufficiently two aspects of engagement-its two-way nature, and the extent to which engaged employees are expected to have an element of business awareness, even though it appears that engagement overlaps with the two concepts. Rafferty et al (2005) also distinguish employee engagement and the two prior concepts- Commitment and OCB, on the ground that engagement clearly demonstrates that it is a two-way mutual process between the employee and the organization.

\subsection{Definition of Employee Engagement}

To date, there is no single and generally accepted definition for the term employee engagement. This is evident if one looks at the definitions forwarded for the term by three well-known research organizations in human resource area, let alone individual researchers. Below are the definitions:

Perrin's Global Workforce Study (2003) uses the definition "employees' willingness and ability to help their company succeed, largely by providing discretionary effort on a sustainable basis." According to the study, engagement is affected by many factors which involve both emotional and rational factors relating to work and the overall work experience.

Gallup organization defines employee engagement as the involvement with and enthusiasm for work. Gallup as cited by Dernovsek (2008) likens employee engagement to a positive employees' emotional attachment and employees' commitment.

Robinson et al. (2004) define employee engagement as "a positive attitude held by the employee towards the organization and its value. An engaged employee is aware of business context, and works with colleagues to improve performance within the job for the benefit of the organization. The organization must work to develop and nurture engagement, which requires a two-way relationship between employer and employee."

This verdict and definition forwarded by Institute of Employment Studies gives a clear insight that employee engagement is the result of two-way relationship between employer and employee pointing out that there are things to be done by both sides. Furthermore, Fernandez (2007) shows the distinction between job satisfaction, the well-known construct in management, and engagement contending that employee satisfaction is not the same as employee engagement and since managers can not rely on employee satisfaction to help retain the best and the brightest, employee engagement becomes a critical concept. Other researchers take job satisfaction as a part of engagement, but it can merely reflect a superficial, transactional relationship that is only as good as the organization's last round of perks and bonuses; Engagement is about passion and commitment-the willingness to invest oneself and expand one's discretionary effort to help the employer succeed, which is beyond simple satisfaction with the employment arrangement or basic loyalty to the employer (BlessingWhite, 2008; Erickson, 2005; Macey and Schnieder ,2008). Therefore, the full engagement equation is obtained by aligning maximum job satisfaction and maximum job contribution. Stephen Young, the executive director of Towers Perrin, also distinguishes between job satisfaction and engagement contending that only engagement (not satisfaction) is the strongest predictor of organizational performance (Human Resources, 2007).

Recent researches also indicate that Employee commitment and OCB are important parts and predictors of employee engagement in that commitment is conceptualized as positive attachment and willingness to exert energy for success of the organization, feeling proud of being a member of that organization and identifying oneself with it and OCB is a behaviour observed within the work context that demonstrates itself through taking 
innovative initiatives proactively seeking opportunities to contribute one's best and going extra mile beyond employment contract. However, these constructs constitute the bigger construct employee engagement and they can not independently act as a replacement for engagement (Macey and Schneider, 2008; Robinson et al, 2004).

The bad news for management is that global surveys conducted by survey houses and research organizations indicate that significant size of employees are disengaged being sceptical of any organizational initiative or communication and rather more likely indulging in contagious negativity (Dernovsek, 2008; Perrin, 2003; Ellis and Sorensen, 2007; BlessingWhite, 2008). The problem with these surveys is that they use their own items to measure employee engagement. If looked at the available literatures on measuring employee engagement, one would get surprisingly several measurement items to the extent that it seems different constructs are being measured (Robinson et al, 2004; Cohen and Higgins, 2007; Perrin, 2003; Ellis and Sorenson, 2007; Dernovsek, 2008). Future researches are expected to come up with clear definition and dimensions of employee engagement on basis of which the level of engagement can be measured thereby pointing out to managers the roadmap for fully engaging employees in their job. As the old saying goes "what you can't measure, you can't manage". Thus, there is a call for future researches, as suggested by Endres and Mancheno-Smoak (2008), to define engagement in clear terms to avoid interpretation by subsequent users giving to the construct different meanings.

\section{Drivers of Employee Engagement}

Many researches have tried to identify factors leading to employee engagement and developed models to draw implications for managers. Their diagnosis aims to determine the drivers that will increase employee engagement level.

According to Penna research report (2007) meaning at work has the potential to be valuable way of bringing employers and employees closer together to the benefit of both where employees experience a sense of community, the space to be themselves and the opportunity to make a contribution, they find meaning. Employees want to work in the organizations in which they find meaning at work. Penna (2007) researchers have also come up with a new model they called "Hierarchy of engagement" which resembles Maslow's need hierarchy model. In the bottom line there are basic needs of pay and benefits. Once an employee satisfied these needs, then the employee looks to development opportunities, the possibility for promotion and then leadership style will be introduced to the mix in the model. Finally, when all the above cited lower level aspirations have been satisfied the employee looks to an alignment of value-meaning, which is displayed by a true sense of connection, a common purpose and a shared sense of meaning at work.

The BlessingWhite (2006) study has found that almost two third's (60\%) of the surveyed employees want more opportunities to grow forward to remain satisfied in their jobs. Strong manager-employee relationship is a crucial ingredient in the employee engagement and retention formula.

Development Dimensions International (DDI, 2005) states that a manager must do five things to create a highly engaged workforce. They are:

- Align efforts with strategy

- Empower

- Promote and encourage teamwork and collaboration

- Help people grow and develop

- Provide support and recognition where appropriate

The Towers Perrin Talent Report (2003) identifies the top ten work place attributes which will result in employee engagement. The top three among the ten drivers listed by Perrin are: Senior management's interest in employees' well-being, Challenging work and Decision making authority.

After surveying 10,000 NHS employees in Great Britain, Institute of Employment Studies (Robinson et al., 2004) points out that the key driver of employee engagement is a sense of feeling valued and involved, which has the components such as involvement in decision making, the extent to which employees feel able to voice their ideas, the opportunities employees have to develop their jobs and the extent to which the organization is concerned for employees' health and well-being.

CIPD (2006) on the basis of its survey of 2000 employees from across Great Britain indicates that communication is the top priority to lead employees to engagement. The report singles out having the opportunity to feed their views and opinions upwards as the most important driver of people's engagement. The report also identifies the importance of being kept informed about what is going on in the organization. 
The oldest consulting organization in conducting engagement survey, Gallup has found that the manager is the key to an engaged work force. James Clifton, CEO of Gallup organization indicates that employees who have close friendships at work are more engaged workers (Clifton, 2008). Vance (2006) explains the fact that employee engagement is inextricably linked with employer practices. To shed light on the ways in which employer practices affect job performance and engagement, he presents a job performance model. According to him, Employee engagement is the outcome of personal attributes such as knowledge, skills, abilities, temperament, attitudes and personality, organizational context which includes leadership, physical setting and social setting and HR practices that directly affect the person, process and context components of job performance.

Most drivers that are found to lead to employee engagement are non-financial in their nature. Therefore, any organization who has committed leadership can achieve the desired level of engagement with less cost of doing it. This does not mean that managers should ignore the financial aspect of their employees. In fact, performance should be linked with reward. Nevertheless, this is simply to repeat the old saying of Human Relations Movement which goes "as social being, human resource is not motivated by money alone." As Buckingham and Coffman (2005) said, pay and benefits are equally important to every employee, good or bad. A company's pay should at least be comparable to the market average. However, bringing pay and benefits package up to market levels, which is a sensible first step, will not take a company very far- they are like tickets to the ballpark, -they can get the company into the game, but can't help it win.

\section{Employee Engagement and Organizational Performance}

Why should companies invest in employee engagement? The answer is because employee engagement is interwoven significantly with important business outcomes. In this part we will see how employee engagement impacts organizational performance in the light of various research works done.

Studies have found positive relationship between employee engagement and organizational performance outcomes: employee retention, productivity, profitability, customer loyalty and safety. Researches also indicate that the more engaged employees are, the more likely their employer is to exceed the industry average in its revenue growth. Employee engagement is found to be higher in double-digit growth companies. Research also indicates that engagement is positively related to customer satisfaction (Coffman, 2000; Ellis and Sorensen, 2007; Towers Perrin Talent Report, 2003; Hewitt Associates, 2004; Heintzman and Marson, 2005; Coffman and Gonzalez-Molina, 2002).

Engaged employee consistently demonstrates three general behaviours which improve organizational performance:

- Say-the employee advocates for the organization to co-workers, and refers potential employees and customers

- Stay-the employee has an intense desire to be a member of the organization despite opportunities to work elsewhere

- Strive-the employee exerts extra time, effort and initiative to contribute to the success of the business ( Baumruk and Gorman, 2006)

What will happen to an organization if its employees are disengaged? Employees who are not engaged are likely to be spinning (wasting their effort and talent on tasks that may not matter much), settling (certainly do not show full commitment, not dissatisfied enough to make a break) and splitting (they are not sticking around for things to change in their organization), have far more misgivings about their organization in terms of performance measures such as customer satisfaction (BlessingWhite, 2006; Perrin Report, 2003). Meere (2005) based on the survey conducted by ISR on 360000 employees from 41 companies in the world's 10 economically strong countries finds that both operating margin and net profit margins reduced over a three year period in companies with low engagement, while these measures increased over the specified period in companies with high levels of engagement.

Financial News, March 2001, as cited by Accord Management Systems (2004), reveals that disengaged employees are more likely to cost their organization. According to the report, Employees who are disengaged:

- Miss an average of 3.5 more days per year

- Are less productive

- Cost the US economy \$292 to \$355 billion per year 


\section{Employee Engagement Strategies}

So far we have discussed the evolution and definition of employee engagement, the factors that affect it and importance of employee engagement explaining how it is linked to business performance. Now, at this stage any inquisitive reader may ask a question: So what? Employee engagement strategies listed below answer this question. In order to have engaged employees in any organization, managers need to look at the following ten points. We can call these points "tablets" because it is believed that they will cure employee disengagement diseases. Take these ten tablets:

1. Start it on day one: Most organizations do have clear new talent acquisition strategies. However, they lack employee retention strategies. Effective recruitment and orientation programs are the first building blocks to be laid on the first day of the new employee. Managers should be careful in pooling out the potential talent of the new employee through effective recruitment. The newly hired employee should be given both general orientation which is related to the company mission, vision, values, policies and procedures and job-specific orientation such as his/her job duties, and responsibilities, goals and current priorities of the department to which the employee belongs in order to enable him/her to develop realistic job expectations and reduce role conflict that might arise in the future. After the hiring decision is made, the manager has to ensure role-talent fit when placing an employee in a certain position and exert all managerial efforts needed to retain that talent in the organization.

2. Start it from the top: Employee engagement requires leadership commitment through establishing clear mission, vision and values. Unless the people at the top believe in it, own it, pass it down to managers and employees, and enhance their leadership, employee engagement will never be more than just a "corporate fad" or "another HR thing". Employee engagement does not need lip-service rather dedicated heart and action-oriented service from top management. It requires "Leading by Being example"

3. Enhance employee engagement through two-way communication: Managers should promote two-way communication. Employees are not sets of pots to which you pour out your ideas without giving them a chance to have a say on issues that matter to their job and life. Clear and consistent communication of what is expected of them paves the way for engaged workforce. Involve your people and always show respect to their input. Share power with your employees through participative decision making so that they would feel sense of belongingness thereby increasing their engagement in realizing it.

4. Give satisfactory opportunities for development and advancement: Encourage independent thinking through giving them more job autonomy so that employees will have a chance to make their own freedom of choosing their own best way of doing their job so long as they are producing the expected result. Manage through results rather than trying to manage all the processes by which that result is achieved.

5. Ensure that employees have every thing they need to do their jobs: Managers are expected to make sure that employees have all the resources such as physical or material, financial and information resources in order to effectively do their job.

6. Give employees appropriate training: Help employees update themselves increasing their knowledge and skills through giving appropriate trainings. Generally it is understood that when employees get to know more about their job, their confidence increases there by being able to work without much supervision from their immediate managers which in turn builds their self-efficacy and commitment.

7. Have strong feedback system: Companies should develop a performance management system which holds managers and employees accountable for the level of engagement they have shown. Conducting regular survey of employee engagement level helps make out factors that make employees engaged. After finalizing the survey, it is advisable to determine all the factors that driving engagement in the organization, then narrow down the list of factors to focus on two or three areas. It is important that organizations begin with a concentration on the factors that will make the most difference to the employees and put energy around improving these areas as it may be difficult to address all factors at once. Managers should be behind such survey results and develop action-oriented plans that are specific, measurable, and accountable and time- bound.

8. Incentives have a part to play: Managers should work out both financial and non-financial benefits for employees who show more engagement in their jobs. Several management theories have indicated that 
when employees get more pay, recognition and praise, they tend to exert more effort into their job. There should be a clear link between performance and incentives given to the employees.

9. Build a distinctive corporate culture: Companies should promote a strong work culture in which the goals and values of managers are aligned across all work sections. Companies that build a culture of mutual respect by keeping success stories alive will not only keep their existing employees engaged but also they baptize the new incoming employees with this contagious spirit of work culture.

10. Focus on top-performing employees: A study conducted by Watson Wyatt Worldwide in 2004/05 on HR practices of 50 large USA firms shows that high-performing organizations are focusing on engaging their top-performing employees. According to the finding of the same research, what high-performing firms are doing is what top-performing employees are asking for and this reduces the turnover of high-performing employees and as a result leads to top business performance.

Note that there is lack of sufficient literature on what could be the challenges that entangle with leaders' effort to improve their employee engagement scores. Most researches on the area focus on identifying the drivers or factors leading to engagement; however, failing to indicate clearly articulated strategies to get employees engaged in their work. The suggested strategies will definitely have financial implications on organizations. However, researches do not lucidly show the cost of efforts aimed at increasing employee engagement.

\section{Conclusion}

To date, there is no generally accepted definition for employee engagement. However, there is growing consensus among the authors that the construct is distinguishable from related concepts in management such as employee commitment, organizational citizenship behaviour and job satisfaction in such a manner that employee engagement clearly reflects the two-way exchange of effort between employees and employers, and it has stretched meaning beyond the aforementioned constructs. Research on engagement is still on its infancy, attempting to come up with more clear-cut and acceptable definition.

Most studies demonstrate that feeling valued by management, two-way communication between management and employees, management's interest in employees' well-being and giving more opportunities for employees to grow are the top drivers of employee engagement. Nevertheless, as studies indicate, employees do not give much importance to pay and benefits. This might be the case because almost all the surveys were made in companies working in economically-well-to-do countries. The priorities of drivers might have varied if similar surveys were undergone in other third world countries, like African countries. Therefore, there is a need for more global surveys including more number of countries.

The literatures indicate that employee engagement is closely linked with organizational performance outcomes. Companies with engaged employees have higher employee retention as a result of reduced turnover and reduced intention to leave the company, productivity, profitability, growth and customer satisfaction. On the other hand, companies with disengaged employees suffer from waste of effort and bleed talent, earn less commitment from the employees, face increased absenteeism and have less customer orientation, less productivity, and reduced operating margins and net profit margins. Most researches emphasize merely the importance and positive impacts of employee engagement on the business outcomes, failing to provide the cost-benefit analysis for engagement decisions. As any other management decisions, engagement decision should be evaluated in terms of both its benefits and its associated costs, without giving greater emphasis to neither of the two, not to bias the decision makers. Thus there is a need to study the cost aspect of engagement decisions. The remarkable fact is, the findings of today's researches, can be used as corner stone for the building of complete essence to the construct. Furthermore, much of the works related to "employee engagement" construct is attributed to survey houses and consultancies. Therefore, there is a need for academia to investigate this new construct and come up with a clear definition and dimensions that will be used for measuring employee engagement justifying the importance of engagement concept. Otherwise, it will pass away shortly as many other human resource fads did.

Findings of various researches suggest their own strategies in order to keep employees engaged. Here in this article ten points or strategies called "the ten tablets" were suggested to keep employees engaged. For managers, work of employee engagement starts at day one through effective recruitment and orientation program, the work of employee engagement begins from the top as it is unthinkable to have engaged people in the organizations where there are no engaged leadership. Managers should enhance two-way communication, ensure that employees have all the resources they need to do their job, give appropriate training to increase their knowledge and skill, establish reward mechanisms in which good job is rewarded through various financial and non-financial incentives, build a distinctive corporate culture that encourages hard work and keeps success stories alive, develop a strong performance management system which holds managers and employees 
accountable for the behaviour they bring to the workplace, place focus on top-performing employees to reduce their turnover and maintain or increase business performance.

\section{References}

Accord Management Systems. (2004). Employee Engagement Strategy: A Strategy of Analysis to Move from Employee Satisfaction to Engagement. [Online] Available: www.accordsyst.com/papers/engagement_wp.pdf (March 3, 2009)

Baumruk R., and Gorman B. (2006). Why managers are crucial to increasing engagement. Melcrum Publishing.

Blessing White. (2006). Employee Engagement Report 2006 BlessingWhite, Inc. Princeton, New Jersey. [Online] Available: www.blessingwhite.com (November 15, 2008)

Blessing White. (2008). The Employee Engagement Equation in India. Presented by BlessingWhite and HR Anexi. [Online] Available: www.blessingwhite.com (November 15, 2008)

Buckingham M., and Coffman C. (2005). First, break all the rules. Pocket Books, London.

Chartered Institute of Personnel and Development. (2006). Reflections on employee Engagement: Change agenda. CIPD: London. [Online] Available: http://www.cipd.co.uk/changeagendas (November10, 2008)

Clifton, James K. (2008). Engaging your employees: Six keys to understanding the new workplace. 2002 SHRM Foundation Thought Leaders Remarks. Society for Human Resource Management

Coffman C. (2000). Is Your Company Bleeding Talent? How to become a true "employer of choice". The Gallup Management Journal, 2000. The Gallup Organization, Princeton, NJ

Coffman, C., and Gonzalez-Molina, G. (2002). Follow this Path: How the world's greatest organizations drive growth by unleashing human potential. New York Warner Books, Inc.

Cohen G., and Higgins N. J. (2007). Employee Engagement: The secret of highly performing organizations. Journal of Applied Human Capital Management, Vol 1 Number 2007.

Dernovsek D. (2008). Creating highly engaged and committed employee starts at the top and ends at the bottom line Credit Union Magazine, May 2008. Credit Union National Association, Inc.

Development Dimensions International. (2005). (Predicting Employee Engagement MRKSRR12-1005 Development Dimensions International, Inc., MMV. [Online] Available:www.ddiworld.com (October 30,2008)

Ellis C. M., and Sorensen A. (2007). Assessing Employee Engagement: The Key to Improving Productivity. Perspectives, vol .15, Issue 1 The Segal Group, Inc.

Endres G. M., and Mancheno-Smoak L. (2008). The Human resource Craze: Human Performance Improvement and Employee Engagement. Organizational Development Journal, Spring 2008; 26, 1; ABI/ INFORM Global pg 69-78

Erickson, T.J. (2005). Testimony submitted before the US Senate Committee on Health, Education, Labour and Pensions, May 26.

Fernandez. C.P. (2007). Employee engagement. Journal of Public Health Management and Practice. [Online] Available: http://find.galegroup.com. (October 30, 2008)

Heintzman R., and Marson B. (2005). People, service and trust: Links in a public sector service value chain. International Review of Administrative Studies, Vol 7 (4) December 2005, pp 549-575.

Hewitt Associates. (2004). Employee engagement higher at double digit growth companies. Research Brief. Hewitt associates LLC.

Human Resources. (2007). Research: Employee engagement ROI-rules of engagement [Online] Available: http://global.factiva.com/ha/default.aspx. (October 28, 2008)

Macey W.H and Schneider B. (2008). The Meaning of Employee Engagement. Industrial and Organizational Psychology, 1 (2008), 3-30.

Meere M. (2005). High cost of disengaged employees Victoria: Swinburne University of Technology. [Online] Available:http://www.swinburne.edu.au/corporate/industrysolutions/ee/reports/Employee\%20Engagement\%20in dustry\%20Breifing\%20Paper\%20Dec\%202005\%20.pdf (October 30, 2008)

Melcrum publishing. (2005). Employee engagement: How to build a high-performance workforce. An independent Melcrum Research Report Executive Summary. 
Penna (2007). Meaning at Work Research Report. [Online] Available: http:// www. e-penna.com/ newsopinion /research.aspx (November10, 2008)

Perrin T. (2003). Working Today: Understanding What Drives Employee Engagement The 2003 Towers Perrin Talent Report U.S Report. [Online] Available: http://www.towersperrin.com/tp/getwebcachedoc? Webc $=$ HRS /USA/2003/200309/Talent_2003.pdf (October 30, 2008)

Rafferty A. M., Maben J., West E., and Robinson D. (2005). What makes a good employer? Issue Paper 3 International Council of Nurses Geneva

Robinson D., Perryman S., and Hayday S. (2004). The Drivers of Employee Engagement Report 408, Institute for Employment Studies, UK

Vance R. J. (2006). Employee Engagement and Commitment SHRM Foundation, USA

Watson Wyatt Worldwide. (2005). Employee Engagement and Talent Management. [Online] Available: www.watsonwyatt.com (March 3, 2009) 